\title{
Comunicação
}

[Communication]

\section{Níveis séricos de enzimas de função hepática em frangos de corte de criação industrial clinicamente saudáveis}

[Serum levels of hepatic enzyme function in clinically healthy broiler chickens]

\author{
A. Borsa, A. Kohayagawa, L.P. Boretti, M.E. Saito, K. Kuibida \\ Faculdade de Medicina Veterinária e Zootecnia - UNESP \\ Caixa Postal 560 \\ 18618-000 - Botucatu, SP
}

\begin{abstract}
Variáveis bioquímicas têm sido usadas como auxiliares do diagnóstico das enfermidades nos animais domésticos, contudo, existem poucos trabalhos sobre os níveis de referência dessas variáveis em aves, sendo talvez a causa da não utilização de exames de laboratório na área de patologia aviária.
\end{abstract}

As enzimas hepáticas costumeiramente incluídas nos perfis de triagem bioquímica sérica são: alanina-aminotransferase (ALT) ou transaminase glutâmico pirúvica (TGP), aspartato aminotransferase (AST) ou transaminase glutâmico-oxalacética (TGO), fosfatase alcalina (FA), lactato desidrogenase (LDH) e gama glutamiltransferase (GGT) (Ferreira Neto et al., 1978; Duncan, 1982; Meyer et al., 1995).

A elevação dos níveis sérico-enzimáticos atribuída à disfunção hepática pode ser decorrente da ruptura dos hepatócitos, resultantes de necrose, ou das alterações na permeabilidade da membrana celular (ALT, AST e LDH) ou do processo de colestase (FA e GGT) (Kaneko,1989).

O diagnóstico das enfermidades hepáticas em aves, segundo Lumeij e Westerhof (1987), não é uma prática muito simples, pois nem sempre se observa a correlação entre alterações dos níveis séricos de enzimas hepáticas e a patologia do fígado.

Nesta pesquisa, utilizaram-se 125 frangos de corte, machos, linhagem Ross, clinicamente saudáveis, criados em sistema de criação industrial (Lana, 2000), vacinados no primeiro dia de idade contra doença de Marek, bouba aviária e doença de Gumboro, mantidos durante todo o período com água e ração comercial $a d$ libitum.

Analisaram-se cinco amostras de sangue para cada faixa etária $(7,14,21$ e 28,35 e 42 dias de idade), sendo as colheitas realizadas por meio de punção da veia ulnar. Após a colheita, as amostras foram imediatamente centrifugadas a $3000 \mathrm{rpm}$ para a separação do soro. As amostras de soro foram, então, congeladas a $-20^{\circ} \mathrm{C}$ até o momento da realização das análises, que ocorreram em até 48 horas.

Foram realizados pools de amostras de soro para cada idade. Assim, aos sete dias de idade, foram usadas 10 aves por amostra, aos 14, cinco, aos 21 e 28 dias, três, e aos 35 e 42 dias, duas, totalizando 125 aves.

As enzimas foram determinadas por método cinético (Kaneko, 1989), com o uso de kit

Recebido em 11 de fevereiro de 2005

Aceito em 30 de janeiro de 2006.

E-mail: borsadri@unoeste.br 
comercial $^{1}$, calculando-se a média de três leituras, com 60 segundos de intervalo, utilizando-se filtro de $340 \mathrm{~nm}$ para ALT, AST e $\mathrm{LDH}$ e $405 \mathrm{~nm}$ para $\mathrm{FA}$ e GGT a $37^{\circ} \mathrm{C}$, em enzimômetro $^{2}$.

Os resultados foram submetidos à análise de variância. Para as comparações de médias, usouse teste Tukey, com nível de significância de 5\%, utilizando-se o programa SAS (User's... 1996).
Os índices de produção, como consumo médio de ração, conversão alimentar, ganho de peso e mortalidade ficaram dentro da média brasileira para a criação de frangos de corte em sistema industrial, descritos por Lana (2000). Não foram observadas alterações clínicas nos tempos de dosagem.

Não houve alterações significativas nos níveis das enzimas estudadas em relação à idade das aves (Tab. 1).

Tabela 1. Valores médios, desvio-padrão e variação dos níveis das enzimas aspartato aminotransferase (AST), alanina aminotransferase (ALT), gama glutamiltransferase (GGT), fosfatase alcalina (FA) e lactato desidrogenase (LDH) em frangos de corte de diferentes idades

\begin{tabular}{|c|c|c|c|c|c|}
\hline \multirow[t]{2}{*}{$\begin{array}{l}\text { Idade } \\
\text { (dias) }\end{array}$} & \multicolumn{5}{|c|}{ Enzima (UI/1) } \\
\hline & AST & ALT & LDH & FA & GGT \\
\hline \multirow[t]{2}{*}{7} & $300 \pm 262$ & $8 \pm 4$ & $5032 \pm 1794$ & $14348 \pm 3579$ & $13 \pm 4$ \\
\hline & $(259-332)$ & $(2-13)$ & $(3400-7480)$ & $(11008-18378)$ & $(9-21)$ \\
\hline \multirow[t]{2}{*}{14} & $221 \pm 17$ & $15 \pm 4$ & $2244 \pm 1075$ & $14043 \pm 3590$ & $18 \pm 4$ \\
\hline & $(208-251)$ & $(9-22)$ & $(891-3690)$ & $(9009-18291)$ & $(13-24)$ \\
\hline \multirow[t]{2}{*}{21} & $221 \pm 60$ & $26 \pm 8$ & $2885 \pm 744$ & $4324 \pm 493$ & $14 \pm 3$ \\
\hline & $(202-325)$ & (14-34) & $(1894-3692)$ & $(3670-4782)$ & $(9-17)$ \\
\hline \multirow[t]{2}{*}{28} & $170 \pm 28$ & $24 \pm 9$ & $2161 \pm 227$ & $2601 \pm 1372$ & $15 \pm 3$ \\
\hline & $(126-200)$ & $(16-40)$ & $(2020-2555)$ & $(868-4554)$ & $(11-19)$ \\
\hline \multirow[t]{2}{*}{35} & $180 \pm 22$ & $25 \pm 4$ & $2929 \pm 131$ & $3758 \pm 3118$ & $24 \pm 7$ \\
\hline & $(162-221)$ & $(21-34)$ & $(1431-4163)$ & $(1284-9172)$ & $(11-30)$ \\
\hline \multirow[t]{2}{*}{42} & $209 \pm 17$ & $7 \pm 7$ & $2874 \pm 1080$ & $3510 \pm 706$ & $20 \pm 2$ \\
\hline & $(202-229)$ & $(4-14)$ & $(1545-3262)$ & $(2310-4110)$ & $(17-24)$ \\
\hline
\end{tabular}

Os níveis séricos da AST, determinados neste trabalho, foram inferiores aos encontrados por Giroir et al. (1991) e semelhantes aos encontrados por Saukas et al. (1994), Fernandez et al. (1994) e Krasnodebska-Depta e Koncicki (1999), que também não observaram efeito da idade sobre a variação dos níveis dessa enzima.

Os valores de LDH foram inferiores aos apresentados por Saukas et al. (1994) e similares aos encontrados por Fernandez et al. (1994) e Krasnodebska-Depta e Koncicki (1999) aos sete, 14 e 21 dias de idade das aves. Há grande concentração nas hemácias dessa enzima, por essa razão, resultados diferentes entre autores podem estar relacionados à presença de hemólise, mesmo em pequenas quantidades no soro das aves (Kramer, 1989).

Foram observados níveis inferiores da GGT em relação aos dados apresentados por Saukas et al.

\footnotetext{
${ }^{1}$ CELM - Cia. Equip. Laboratórios Modernos. Barueri, SP.

${ }^{2}$ QUICK Lab. Porto Alegre, RS.
}

(1994) e por Fernandez et al. (1994), em aves clinicamente saudáveis.

As variações nos níveis séricos das diferentes enzimas estudadas em relação aos resultados encontrados por outros autores podem estar relacionadas aos kits comerciais, à aparelhagem usada para as dosagens e ao método de colheita de amostras e da obtenção do soro.

Ressalta-se que fatores relacionados ao clima, ao tipo de alimentação e ao manejo podem refletir nos resultados das análises, impossibilitando $\mathrm{o}$ uso de valores determinados em outros países como referência. Por essa razão, é importante a determinação dos parâmetros bioquímicos em aves nas condições brasileiras.

Os resultados sugerem que não há alterações nos níveis séricos das enzimas analisadas em frangos de corte de criação industrial nas épocas analisadas.

Palavras-chave: frango de corte, enzima, nível sérico, valores de referência 


\begin{abstract}
The values for the main hepatic enzymes included in the profiles of screen clinical biochemistry, alanineaminotransferase (ALT), aspartate aminotransferase (AST), alkaline phosphatase (FA), lactate desidrogenase (LDH) and gamaglutamiltransferase (GGT), in samples of serum of broiler chickens in industrial system, clinically healthy, starting from the seventh day of life, until the slaughter (42 days) in weekly intervals were determined. Significant variations were not observed in the analyses in relation to the age of the birds for none of the appraised enzymes.
\end{abstract}

Keywords: broiler chicken, serum enzymes, reference values

\section{REFERÊNCIAS BIBLIOGRÁFICAS}

DUNCAN, J.R.; PRASSE, K.W. Patologia clínica veterinária. São Paulo: Guanabara Koogan, 1982. 217p.

FERNANDEZ, A.; VERDE, M.T.; GASCON, $M$. Variations of clinical biochemical parameters of laying hens and broiler chickens fed aflatoxin containing feed. Avian Pathol., v.23, p.37-47, 1994.

FERREIRA-NETO, J.M.; VIANA, E.S. Patologia clínica veterinária. Belo Horizonte: Rabelo Brasil, 1978. 279p.

GIROIR, L.E.; HUFF, W.E.; KUBENA, L.F. The individual and combined toxicity of kojic acid and aflatoxin in broiler chickens. Poult. Sci., v.70, p.1351-1356, 1991.

KANEKO, J.J. Clinical biochemistry of domestic animals. 4.ed. San Diego: Academic, 1989. 932p.

KRAMER, J.W. Clinical enzimology. In: KANEKO, J.J. Clinical biochemistry of domestic animal. San Diego: Academic, 1989. p.338-363.
KRASNODEBSKA-DEPTA, A.; KONCICKI, A. Physiological values of hematological indices in chickens. Poult. J. Vet. Sci., v.2, p. 165-170, 1999.

LANA, G.R.Q. Avicultura. Campinas: Ed. Rural, 2000. 268 p.

LUMEIJ, J.T.; WESTERHOF, Blood chemistry for the diagnosis of hepatobiliary disease in birds. A review. Vet. Q., v.9, p.255-61, 1987.

MEYER, D.J.; COLES, E.H.; RICH,L, J. Medicina de laboratório veterinário: interpretação e diagnóstico. São Paulo: Roca, 1995. 308 p.

SAUKAS, T.N.; KOHAYAGAWA, A.; CURY, P.R. Níveis de enzimas séricas em frangos de corte. In: CONGRESSO BRASILEIRO DE MEDICINA VETERINÁRIA, 23., 1994, Recife. Anais... Recife: SPMV, 1994. p.87 (Resumo).

USER'S guide: statistical analysis system. Release 6.11. Cary, NC: SAS Institute, 1996. 